\title{
Prediction of beef carcass and selected primal subcutaneous fat yields using data from images captured on-line in abattoir
}

\author{
N. Prieto ${ }^{1}$, D.W. Ross ${ }^{1}$, E.A. Navajas ${ }^{1}$, R.I. Richardson ${ }^{2}$, J.J. Hyslop ${ }^{3}$, C. Craigie $^{1}$, G. Simm ${ }^{1}$, R. Roehe ${ }^{1}$
}

${ }^{1}$ Sustainable Livestock Systems Group, Scottish Agricultural College, West Mains Road, Edinburgh EH9 3JG, United Kingdom, ${ }^{2}$ University of Bristol, Division of Farm Animal Science, Bristol, BS40 5DU, United Kingdom, ${ }^{3}$ Select Services, Scottish Agricultural College,West Mains Road, Edinburgh EH9 3JG, United Kingdom

Email: etcnpb00@estudiantes.unileon.es

Introduction Current grading methods for fat yield in UK abattoirs are limited to subjective fat classification score based on the EUROP based system. Video image analyses (VIA) methods have previously been employed commercially to estimate fat classification and carcass yield in other EU countries. Recently, fat trim yield has been strongly predicted $\left(\mathrm{R}^{2}=\right.$ 0.8 ) by VIA system (Vote et al., 2009) and fat thickness measured manually has shown to correlate with intramuscular fat content (Indurain et al., 2009). Carcass and primal fat-yield information would be commercially useful in determining the quality and value of primal cuts. The aim of this study was to assess the potential of predicting half carcass and selected primal-cut subcutaneous fat yield using features extracted from high-resolution carcass digital images taken on-line at chain speed.

Material and methods Cross-bred steers and heifers $(n=29$; sired by either Aberdeen Angus or Limousin bulls) were used in this study. The animals were slaughtered at an average carcass weight and age at slaughter of $340(\mathrm{SD}=33.7) \mathrm{kg}$ and $584(\mathrm{SD}=60.0)$ days, respectively. Images were captured of left exterior and right interior carcass side, both orthogonal to carcass split dissection plane adjacent to grading area of the line using a high resolution digital camera (2592 by 1944 pixel) capturing colour images. All images were spatially corrected for distortion to enable dimensional extraction. Software processing algorithms were developed using Inspector analysis package (v8, Matrox Electronic. Systems. Ltd, Quebec) to automatically segregate and estimate measure of total subcutaneous fat covering over left half carcass as a planar projected area (CARFA $\left.-\mathrm{mm}^{2}\right)$. Linear dimensions of subcutaneous fat depths were measured manually on images, adjacent to carcass landmark areas $4^{\text {th }}$ rib (4RFD), $8^{\text {th }}$ rib (8RFD), $13^{\text {th }}$ rib (13RFD) and $3^{\text {rd }}$ lumbar (3LFD) on right half carcass, measured as $\mathrm{mm}$. At $48 \mathrm{~h}$ after slaughter, left carcass sides were split into primal cuts that were vacuum packed and subsequently dissected to components. Total weight $(\mathrm{g})$ of subcutaneous fat of half carcass and sample primals: forerib and sirloin (subdivided into $11^{\text {th }}-12^{\text {th }}$ rib section, $13^{\text {th }}$ rib section and lumbar section) were collected. Half carcass and selected primal-cuts' subcutaneous fat yield were predicted using as independent variables: 1) CARFA, by means of Simple Lineal Regression and 2) 4RFD, 8RFD, 13RFD, 3LFD and CARFA, using Partial Least Square Regression. Internal full leave-one-out cross-validation was performed and the predictive ability of the calibration models was evaluated in terms of coefficient of determination $\left(\mathrm{R}^{2}\right)$ and Root Mean Square Error of Cross-Validation (RMSECV) using The Unscrambler program (v8.5.0, Camo, Trondheim, Norway).

Results Calibrations for subcutaneous fat yield of half carcass and selected primal-cuts are presented in Table 1. Estimated projected carcass subcutaneous fat area did not seem to offer any prediction for subcutaneous fat yield of both half carcass and all primal components $\left(\mathrm{R}^{2}\right.$ range: 0.01 to 0.02 ). Adding 4 linear measures of subcutaneous fat depths as independent variables significantly increased the accuracy of prediction in all cases with $\mathrm{R}^{2}$ ranging from 0.48 to 0.62 .

Table 1 Descriptive and prediction statistics for subcutaneous fat yield of half carcass and selected primal-cuts of beef

\begin{tabular}{|c|c|c|c|c|c|c|c|}
\hline \multicolumn{2}{|l|}{ Y variable } & & & \multirow[t]{2}{*}{$\mathrm{X}$ variables } & \multicolumn{3}{|c|}{ Prediction } \\
\hline Subcutaneous fat $(\mathrm{g})$ & Range & Mean & SD & & ns & $\mathrm{R}^{2}$ & RMSECV \\
\hline \multirow[t]{2}{*}{ Half carcass } & $6370-16935$ & 10844 & 2557 & CARFA & 1 & 0.02 & 2798.7 \\
\hline & & & & $4 \mathrm{RFD}+8 \mathrm{RFD}+13 \mathrm{RFD}+3 \mathrm{LFD}+\mathrm{CARFA}$ & 3 & 0.48 & 2224.9 \\
\hline \multirow[t]{2}{*}{ Forerib } & $345-1450$ & 854 & 287.1 & CARFA & 1 & 0.01 & 302.3 \\
\hline & & & & $4 \mathrm{RFD}+8 \mathrm{RFD}+13 \mathrm{RFD}+3 \mathrm{LFD}+\mathrm{CARFA}$ & 3 & 0.62 & 206.7 \\
\hline \multirow[t]{2}{*}{ Sirloin } & $565-1930$ & 1160 & 406.2 & CARFA & 1 & 0.01 & 411.5 \\
\hline & & & & $4 \mathrm{RFD}+8 \mathrm{RFD}+13 \mathrm{RFD}+3 \mathrm{LFD}+\mathrm{CARFA}$ & 3 & 0.55 & 329.7 \\
\hline \multirow[t]{2}{*}{$11-12^{\text {th }}$ rib sirloin } & $145-560$ & 306 & 118.4 & CARFA & 1 & 0.02 & 123.5 \\
\hline & & & & $4 \mathrm{RFD}+8 \mathrm{RFD}+13 \mathrm{RFD}+3 \mathrm{LFD}+\mathrm{CARFA}$ & 3 & 0.37 & 112.5 \\
\hline \multirow[t]{2}{*}{$13^{\text {th }}$ rib sirloin } & $85-325$ & 170 & 59.8 & CARFA & 1 & 0.01 & 62.8 \\
\hline & & & & $4 \mathrm{RFD}+8 \mathrm{RFD}+13 \mathrm{RFD}+3 \mathrm{LFD}+\mathrm{CARFA}$ & 4 & 0.58 & 47.3 \\
\hline \multirow[t]{2}{*}{ Lumbar Sirloin } & $310-1275$ & 684 & 258.6 & CARFA & 1 & 0.01 & 272.4 \\
\hline & & & & 4RFD + 8 RFD + 13RFD+ 3LFD + CARFA & 3 & 0.53 & 215.1 \\
\hline
\end{tabular}

Conclusions Data extracted from high resolution digital images (higher than typical commercial VIA systems) can predict with moderate accuracy subcutaneous fat yield of both half carcass and high value primal cuts. With further development, such as high resolution imagery over whole carcass to accurately assess fat thicknesses in addition to the subcutaneous fat area, this technique could estimate with higher accuracy fat yields relating to carcass quality.

Acknowledgements Financial support for this research was received from the Scottish Government.

References Vote, D.J., Bowling, M.B., Cunha, B.C.N., Belk, K.E., Tatum, J.D., Montossi, F. and Smith, G.C. 2009. Journal of Animal Science 87, 2376-2390.

Indurain, G., Carr, T.R., Goñi, M.V., Insausti, K., Beriain, M.J. 2009. Meat Science 82, 155-161. 